\title{
Current Diagnostic Approach and Initial Treatment Patterns for Renal Colic in Emergency Department
}

\author{
Roshana Shrestha, ${ }^{1}$ Yogendra Bista, ${ }^{2}$ Amir Khan $^{1}$ \\ ${ }^{1}$ Department of Emergency, Manmohan Memorial Medical College and Teaching Hospital, Kathmandu, Nepal, \\ ${ }^{2}$ Department of Radiology, Manmohan Memorial Medical College and Teaching Hospital, Kathmandu, Nepal.
}

\section{ABSTRACT}

Background: Renal colic is a common clinical presentation in emergency. The goal of this study was to describe the epidemiology, current diagnostic and treatment strategies of ureteric colic in our emergency department.

Methods: This is a retrospective study performed over a six months period of patients with clinically suspected renal colic. Data collected included age, sex, urine analysis, ultrasound studies regarding size, site of the stone and presence of hydronephrosis. Comparative statistical analysis was performed using SPSS 12.2 software.

Results: Among the total 201 cases, 134(67\%) had ultrasound performed which yielded ureteric stone in 61/134 (45.5\%) cases, out of which 52.5\% (32/61), 32.8\% (20/61) and 14.8\% (9/61) had stones measuring 5-9.9mm, $\leq 4.9 \mathrm{~mm}$ and $\geq$ $10 \mathrm{~mm}$ respectively. The mean age was $31.6 \pm 11$ with male: female of $3: 1$. Hydronephrosis was strongly correlated with the presence of ureteric stone (sensitivity $-85.2 \%$, specificity- $94.5 \%$, positive predictive value- $92.9 \%$ and negative predictive value of $88.5 \%$ ) and was significantly more common with larger stones $(\mathrm{p}=0.05)$. Hematuria and pyuria was present among $44.3 \%$ (27/61) and 31.1\% (19/61) of the ultrasound confirmed ureteric stones respectively. Nonsteroidal antiinflammatory drugs and smooth muscle relaxants were the most common drug offered.

Conclusions: Ultrasound to detect hydronephrosis, which is the most significant finding, may help to establish the probability of obstruction due to clinically important stone. Absence of hydronephrosis probably suggests small or passed out calculus requiring no immediate urological intervention or may indicate alternate diagnosis. Presence or absence of hematuria cannot be reliable diagnosing and excluding ureteral stones.

Keywords: Hematuria; hydronephrosis; nephrolithiasis; pyuria; renal colic; ureteric colic; urolithiasis.

\section{INTRODUCTION}

Renal colic is one of the most severe pain syndromes commonly presenting to the Emergency department (ED) which presents with acute pain in the flanks due to passage of stones through the ureter. Among the imaging procedure, computed tomography (CT) is the imaging modality of choice, ${ }^{1,2}$ however, several authors have raised concerns about it. , $^{3,4}$ Moreover in developing countries like ours CT scan is not practical due to its unavailability and financial constraints. Unfortunately, there is no rational approach to imaging and management of suspected renal colic in our context. The goal of this study is to describe the epidemiology, current diagnostic and treatment strategies in our ED over last 6 months period.

\section{METHODS}

It is a retrospective study conducted in Manmohan Memorial Teaching Hospital following approval of the institutional review committee of Manmohan Memorial Institute of Health Sciences. All consecutive cases of suspected acute renal colic treated in the emergency department from March- August 2015 were identified retrospectively from the emergency records. The provisional diagnosis of ureteric colic was made by the treating doctor in Emergency department on the basis of clinical history and examination. The exclusion criteria were pregnancy, age less than 10 years, known case of congenital urogenital abnormalities, chronic kidney disease and incomplete records. Hematuria was defined as $\geq 3$ red blood cells (RBC) and pyuria $\geq 4$ white blood cells (WBC) per high-power field in urine. Ultrasound (US) finding regarding size and location of ureteric stone if present, presence of hydronephrosis or other alternative diagnosis was recorded. The US was performed with a $3.5 \mathrm{MHz}$ convex-type transducer (MEDISON ACCUVIX XG) by registered radiologists. Each patient underwent standard renal ultrasound, including evaluation of the kidneys, ureters and bladder. The

Correspondence: Dr Roshana Shrestha, Department of Emergency, Manmohan Memorial Medical College and Teaching Hospital, Kathmandu, Nepal. Email: roshanashrestha@yahoo. com, Phone: 977-9841558332. 
kidneys were evaluated completely in the longitudinal and transverse projections at real time evaluation. The bladder was also evaluated at real time imaging with an attempt to image the ureterovesical junction bilaterally. Longitudinal and transverse images of the bladder were obtained. Real time assessment also included a focused attempt to image the ureters. When depicted, the longitudinal images of the ureters were obtained. The upper ureter extends from the renal pelvis to the upper border of sacrum, the middle ureter extends from upper to lower border of sacrum and the lower/distal ureter extends from lower border of sacrum to the bladder. ${ }^{5}$ The size of the stone was recorded and divided into 3 groups according to its longest dimension: $\leq 4.9 \mathrm{~mm}$, $5-9.9 \mathrm{~mm}$ and $\geq 10 \mathrm{~mm}$. If more than one calculus were detected the largest one was taken into consideration for study purpose. The demographic information, clinical information, medication administered, diagnostic investigation performed was recorded in Microsoft excel 2010 and statistical analysis was done using SPSS 13. Significant value was considered if $\mathrm{P}<0.05$.

\section{RESULTS}

Amongst the total 240 suspected ureteric colic who presented to ED during the study period, 39 cases were excluded due to incomplete data. Of the 201 included patients $111(55.2 \%$,) were men, and the mean age was $29 \pm 13.5$ (range 9-86) years. Among them 70/201 (34.8\%) had hematuria and 67/201 (33.3\%) had pyuria. US was performed amongst $67 \%(134 / 201)$ of the total patient out of which ureteric stones were detected in $45.5 \%(61 / 134)$ of cases, $32.8 \%(44 / 134)$ were reported to be normal, and other abnormalities were reported in $21.6 \%(29 / 134)$ cases. Other diseases of kidneys apart from urolithiasis were detected in 11/29 patients. Gynecological problem, hepatobiliary abnormalities and appendicitis were diagnosed by US in 9/29, 6/29 and $3 / 29$ patients respectively.

The mean age of patients with US proven ureteric stone was $31.6 \pm 11$ with male predominance $(77 \%, 47 / 61)$ $(p=.000)$. Relation of different variables in relation to US diagnosis is shown in table 1 . Hematuria and pyuria was present among $44.3 \%(27 / 61)$ and $31.1 \%(19 / 61)$ of the US confirmed ureteric stones respectively. The incidence of hematuria was similar in both gender whereas pyuria was more common in females $(p=0.04)$. The presence of hematuria and pyuria was not related to the site or size of the stone. Of the 61 US proven cases $52.5 \%$ (32/61), $32.8 \%(20 / 61)$ and $14.8 \%(9 / 61)$ had stones measuring $5-9.9 \mathrm{~mm}, \leq 4.9 \mathrm{~mm}$ and $\geq 10 \mathrm{~mm}$ respectively. Most common location of the ureteric stone detected by US was distal ureter $(67.2 \%, 41 / 61)$ followed by proximal ureter $(14.8 \%, 9 / 61)$, kidney $(9.8 \%, 6 / 61)$ and vesical $(8.2 \%, 5 / 61)$. Relation of different variables in relation to size and site of the stones is illustrated in table2.

Hydronephrosis was strongly correlated with the presence of ureteric stone by US which was statistically significant for both gender $(p=.000)$ (sensitivity $-85.2 \%$, specificity-94.5\%, positive predictive value-92.9\% and negative predictive value of $88.5 \%$ ). All female patients $(n=14)$ with US proven ureteric stone had hydronephrosis, however this was not statistically significant $(p=.09)$. In subgroup analysis by age this was statistically significant up to age of 40 years, however not significant after age of 40 years. Larger stones were significantly more associated with hydronephrosis $(p=.05)$. Hydronephrosis was absent in $65.1 \%(56 / 86)$ of cases without hematuria $(p=0.024)$.

In regards to pain medication, $72.6 \%(146 / 201)$ received a nonsteroidal anti-inflammatory drug (NSAID), $72.6 \%$ $(146 / 201)$ a smooth muscle relaxant, and 9.9\% (20/201) a narcotic alone or with combination with each other. Drugs most commonly administered were Hyoscine Butyl Bromide (67.6\%), Diclofenac (49.2\%), Ketorolac (23.4\%), Drotaverin (5\%), and opioids (10\%). Ten out of 61 US proven ureteric colic required an opioid for pain management, however the need for opioid was not related to gender, presence of hydronephrosis, hematuria, pyuria and size or site of stone. Only $8 / 61$ (13\%) of US proven ureteric colic required admission in the hospital.

Table 1. Variables in relation to Ultrasound diagnosis.

\begin{tabular}{|c|c|c|c|c|c|c|}
\hline Variable & & Normal n (\%) & $\begin{array}{l}\text { Stones } \\
\text { n (\%) }\end{array}$ & $\begin{array}{l}\text { Other } \\
\text { n (\%) }\end{array}$ & Total n (\%) & $P$ value \\
\hline \multirow[t]{2}{*}{ Gender } & Female & $23 / 44(52.3)$ & $14 / 61(23)$ & $18 / 29(62.1)$ & $55 / 134(41)$ & \multirow[t]{2}{*}{$P=.000$} \\
\hline & Male & 21/44(47.7) & $47 / 61(77)$ & $11 / 29(37.9)$ & 79/134(59) & \\
\hline \multirow[t]{2}{*}{ Hydronephrosis } & Absent & $44 / 44(100)$ & $9 / 61(14.8)$ & $25 / 29(86.2)$ & $78 / 134(58.2)$ & \multirow[t]{2}{*}{$P=.000$} \\
\hline & Present & 0 & $52 / 61(85.2)$ & $4 / 29(13.8)$ & $56 / 134(41.8)$ & \\
\hline \multirow[t]{2}{*}{ Hematuria } & Absent & $32 / 44(72.7)$ & $34 / 61(55.7)$ & $20 / 29$ (69) & $86 / 134(64.2)$ & \multirow[t]{2}{*}{$P=.167$} \\
\hline & Present & $12 / 44(27.3)$ & $27 / 61(44.3)$ & $9 / 29(31)$ & $48 / 134(35.8)$ & \\
\hline
\end{tabular}


Current Diagnostic Approach and Initial Treatment Patterns for Renal Colic in Emergency Department

\begin{tabular}{|lllllll|}
\hline Pyuria & Absent & $25 / 44(56.8)$ & $42 / 61(68.9)$ & $19 / 29(65.5)$ & $86 / 134(64.2)$ & $P=.441$ \\
& Present & $19 / 44(43.2)$ & $19 / 61(31.1)$ & $10 / 29(34.5)$ & $48 / 134(35.8)$ & \\
Outcome & Discharge & $40 / 44(90.0)$ & $53 / 61(86.9)$ & $23 / 29(79.3)$ & $116 / 134(86.6)$ & $P=.362$ \\
& Admitted & $4 / 44(9.1)$ & $8 / 61(13.1)$ & $6 / 29(20.7)$ & $18 / 134(13.4)$ & \\
\hline
\end{tabular}

Table 2. Variables in relation to size and site of stone.

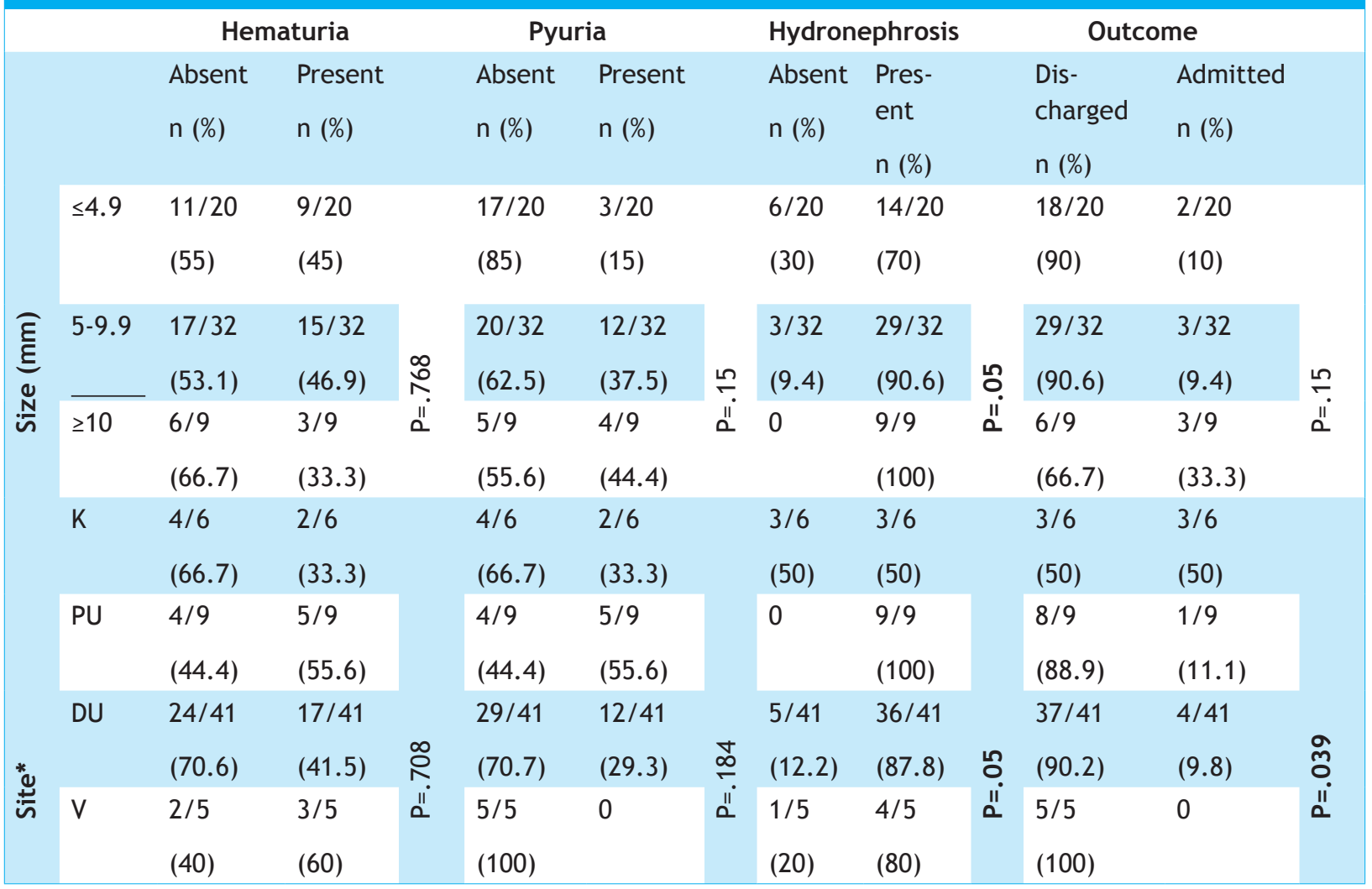

*K=Kidney, PU=Proximal ureter, DU=Distal ureter, V=Vesical.

\section{DISCUSSION}

Hydronephrosis was found to be the most important predictor of ureteric stone in this study. Although all females with US proven ureteric stone had hydronephrosis, the difference was not statistically significant. All cases of ureteric colic with location of stone at proximal ureter (9/9) and $87.8 \%$ (36/41) at distal ureter had hydronephrosis $(p=.05)$. Sensitivity, specificity, positive predictive value and negative predictive value for hydronephrosis in relation to stones in US in this study was $85.2 \%, 94.5 \%, 92.9 \%$ and $88.5 \%$, respectively. In another study, US was 87 percent sensitive and 82 percent specific for the identification of hydronephrosis, which was present in 69 percent of patients with acute ureteral colic. ${ }^{6}$ Hydronephrosis is useful to the clinician if suspicion for stone disease is high, because it can be taken as presumptive evidence of obstructing stone disease ${ }^{7}$ and possibly the size of the obstructing stone. ${ }^{8,9}$ In our study, larger stones were significantly more associated with hydronephrosis. All patients (9/9) with stone $\geq 10 \mathrm{~mm}$ had hydronephrosis and those with 5-9.9 $\mathrm{mm}$ and $\leq 4.9 \mathrm{~mm}$ stone had $90.6 \%$ $(29 / 32)$ and $70 \%(14 / 20)$ hydronephrosis, respectively $(P=0.05)$. Goertz and Lotterman had investigated whether stone size might be predicted based on the degree of hydronephrosis found on US in the initial assessment. In their results, it was shown that patients with moderate and severe hydronephrosis had a significantly higher proportion of stones $\geq 5 \mathrm{~mm}$ than those with mild or no hydronephrosis $(35.4 \%$ vs $12.4 \%, \mathrm{p}<0.001)$. Further more, patients with moderate or severe hydronephrosis had stones $10 \mathrm{~mm}$ or larger compared with patients with mild or no hydronephrosis. ${ }^{8}$ Moak et al. investigated whether hydronephrosis on US could identify potentially troublesome stones and they found that US was able to identify hydronephrosis in 29/38 cases of stone disease and identified no hydronephrosis in 54/69 patients without stones. They further stratified their data by stone size and revealed that patients with hydronephrosis 
were significantly more likely to have a stone $\geq 5 \mathrm{~mm}$ than those without hydronephrosis which concluded that ultrasound was sensitive for detecting clinically relevant stones. ${ }^{9}$ Further more, strength of ultrasound is its ability to detect other diagnosis. In this study, other diseases of kidneys apart from stones were detected in $11 / 29$ patients among which gynecological problem, hepatobiliary system and appendicitis were diagnosed by US in 9/29, 6/29 and 3/29 patients, respectively.

Our study showed that the mean age of patients with US proven ureteric stone was $31.6 \pm 11$ with male predominance $(M: F=3.4: 1)$. This may be due to larger muscle mass in males, more physical work with dehydration. Nephrolithiasis has a peak incidence between 20 and 50 years of age with a predilection for men. ${ }^{10} \mathrm{~A}$ study done in another teaching hospital in Nepal concluded that urinary stones were found to be predominantly among the adult between 20-29 years age group with male predominance $(M: F=1.35: 1)$ and frequency of stone in anatomical site based on kidney, ureter, bladder (KUB) xray was found to be in order kidney>ureter >vesicoureteric junction>pelvic ureteric junction>bladder. ${ }^{11}$ However, a recent study done in developed countries observed a dramatic increase rate of stone disease in females. ${ }^{12}$

Hematuria was detected only amongst $44.3 \%$ (27/61) of US proven urolithiasis and was similar among male and female. The sensitivity, specificity, positive predictive value, and negative predictive value of hematuria on microscopic urinalysis for renal colic using US as the reference in our study was $44 \%, 71 \%, 56 \%$ and $60 \%$, respectively. In a previous study using unenhanced CT as the reference standard, it was $84 \%, 48 \%, 72 \%$, and $65 \%$, respectively. ${ }^{13}$ Thus, our study also demonstrated that presence or absence of hematuria cannot be used to reliably determine which patients actually have ureteral stones. Another article by Lin and Schuur claimed that microscopic hematuria is found in 84 percent of patients with kidney stones; however, due to its presence in other diseases, the specificity is 48 percent. ${ }^{14}$ In this study as well, hematuria was yielded in 31\% (9/29) and $27.3 \%(12 / 44)$ of cases with other diagnosis in US and with normal US, respectively.

In contrast, a study comparing haematuria and intravenous urography produced a sensitivity of $100 \%$ ( $88 \%$ to $100 \%)$ and a specificity of $32 \%$ (21\% to $73 \%$ ), positive predictive value of $64 \%(50 \%$ to $80 \%)$ and a negative predictive value was $100 \%$ (59\% to $100 \%) .{ }^{15}$

Pyuria was detected in $31.1 \%(19 / 61)$ of US proven urolithiasis. The incidence of pyuria was more common in females. A study stated that absence of pyuria was a very good predictor of a negative urine culture, in both febrile and afebrile patients (negative predictive value, $99 \%$ ). But the presence of pyuria was not indicative of positive urine culture (positive predictive value, $25 \%$ ). ${ }^{16}$

In 1996, a large prospective trial by Smith et al. showed that unenhanced helical CT had a high level of accuracy in identifying renal stones with a sensitivity of $97 \%$ and a specificity of $96 \%^{1}$ and finally, in 2000 , they declared: "in relation to stone disease, unenhanced helical CT is truth". ${ }^{2}$ While CT and intravenous urogram (IVU) are accurate diagnostic tests and define clearly the size, shape, and position of ureteric stones, they also present a number of factors that would discourage use ${ }^{10}$ including the potential risks of exposing patients to repeated doses of ionizing radiation. Berrington de Gonzales et al. combined risk-based models with scan frequencies for the United States in 2007 and estimated that 29,000 future cancers might be related to CT scans, with the largest proportion from scans of the abdomen and pelvis. ${ }^{4}$ Patlas et al. compared the accuracy of noncontrast spiral $\mathrm{CT}$ with US for the diagnosis of ureteral calculi in the evaluation of patients with acute flank pain and found that US showed 93\% sensitivity and 95\% specificity in the diagnosis of ureterolithiasis. ${ }^{17}$ Middleton et al. also reported successful use of ultrasonography for renal colic: a $91 \%$ stone detection rate. ${ }^{18}$ Other studies found that ultrasound is only $16 \%$ sensitive for stones $<7$ $\mathrm{mm}$ and $75 \%$ sensitive for those $\geq 7 \mathrm{~mm} .{ }^{19}$ The European Association of Urology in its 2015 Guidelines on Urolithiasis advises that for patients with renal stone disease, imaging procedures should follow clinical examination. Its first imaging choice is ultrasound: "Ultrasonography should be used as the primary procedure. It is a safe (no risk of radiation), reproducible and inexpensive method of urinary stone detection." ${ }^{20}$ CT scan is not available in our hospital and is very expensive in our setting therefore US was the main modality of diagnosis which yielded stone in $45.5 \%(61 / 134)$ of clinically suspected ureteric colic patients. Ultrasonography can also be used to check the abdomen for a possible abdominal aortic aneurysm (AAA) or cholelithiasis and other diseases, which can sometimes be mistaken for acute renal colic. In this study other abnormalities like gynecological problem, hepatobiliary disease, appendicitis and other renal diseases were reported in $21.6 \%(29 / 134)$ cases which facilitated diagnosis of the patient.

Renal colic is frequently described as the worst pain ever experienced, and management of this intense pain is necessary. Consequently, the use of effective pain killers, such as non steroidal anti-inflammatory 
drugs (NSAIDS), spasmolytic agents and opioids, or a combination of medications play important roles in the treatment of these patients. ${ }^{21,22}$

Narcotics have long been used for pain control in renal colic. The benefits of using opioids include low cost, good effect and titration possibility. ${ }^{22}$ However, the majority of physicians are not comfortable with using these drugs due to their side effects which include nausea, vomiting, sedation, dizziness, lightheadedness, narcotic dependence, disorientation, respiratory depression, and hypotension. In our setting, opioids are usually reserved for severe persistent pain and 10 out of 61 US proven ureteric colic required an opioid for pain management, however the need for opioid was not related to gender, presence of hydronephrosis, hematuria, pyuria and size or site of stone.

NSAIDs alone or in combination with other drugs have been used to treat renal colic pain for a long time. A systematic review concluded that patients receiving NSAIDs achieve greater reductions in pain scores and are less likely to require further analgesia in the short term than those receiving opioids. ${ }^{22}$ In this study, $72.6 \%$ of patients with suspected ureteric colic received NSAIDsin the form of Diclofenac(49.2\%) and Ketorolac (23.4\%). Hyoscine butyl bromide (Buscopan TM) is an antimuscarinic drug which blocks the action of acetylcholine at the parasympathetic nerve endings in muscles and glands. ${ }^{23}$ In this study, it was prescribed in $67.6 \%$ of cases either alone or in combination with other drugs. Drotaverine is an inhibitor of Phosphodiesterase 4 (PDE4) in smooth muscles and it has anti-spasmodic activity without anti-muscarinic adverse effects. Romics et al. in their study on the impact of Drotaverine on renal colic pain reported that pain intensity was reduced in more than two-thirds of patients with intravenous drotaverine. ${ }^{24}$ However, during this study, it was used only in $5 \%$ of cases. As this was a retrospective study, pain score and other detailed clinical picture could not be obtained if not recorded in the card. Grade of hydronephrosis was not differentiated in the record therefore couldn't be assessed and studied. Moreover, the US diagnosis was not compared to CT or IVU as standard, therefore even if US was reported as normal some ureteric stones could have been missed.

More recently, 'point-of-care' clinician-performed bedside ultrasound (BUS) has emerged as a diagnostic imaging option when assessing emergency department patients. ${ }^{25}$ Detecting hydronephrosis on BUS is easily learnt. Studies have observed favorable results after short intensive training. ${ }^{26-28}$ Ultrasound is relatively cheap and is recently increasingly being used in emergency department of Nepal by treating physician and it is even available in hospitals at remote places. Focused short training in BUS to the doctors working in Emergency and rural area would greatly improve the diagnosis of patients with suspected renal colic immediately in the ED by reducing need of transferal of patients to radiology , reducing unnecessary imaging of KUB. Thus, for the future, based on this study and various literatures 8,9,2628 there are compelling evidences that the easily learnt skill of BUS may be helpful in managing patients with renal colic. While this technique has been supported by research in emergency medicine, there is no obvious reason why it cannot be learnt in Nepal by all specialty doctors that may be confronted with the renal colic patient, such as emergency physicians, practitioners in nephrology, urology, family practice or general surgery. Further studies and advancement in this area is required in future in our context.

\section{CONCLUSIONS}

US should be widely used in all cases suspected ureteric colic. Hydronephrosis is the most significant finding and the absence of hydronephrosis probably suggests small or passed out calculus requiring no urological intervention or may indicate alternate diagnosis. Hematuria is not a reliable test to determine which patients actually have ureteral stones.

\section{REFERENCES}

1. Smith RC, Verga M, McCarthy S, Rosenfield AT. Diagnosis of acute flank pain: value of unenhanced helical CT. AJR Am J Roentgenol. 1996;166:97-101. [PubMed]

2. Smith RC, Varanelli M. Diagnosis and management of acute ureterolithiasis: CT is truth. AJR Am J Roentgenol. 2000;175:3-6. [PubMed]

3. Broder J, Bowen J, Lohr J, Babcock A, Yoon J. Cumulative CT exposures in emergency department patients evaluated for suspected renal colic. J Emerg Med. 2007;33:1618. [PubMed]

4. Berrington de Gonzales A, Mahesh M, Kim K, Bhargavan M, Lewis R, Mettler F. Projected cancer risks from computed tomographic scans performed in the United States in2007. Arch Intern Med. 2009;169(22):2071-7. [PubMed]

5. Benninghoff A. Gross anatomy, embryology and histology of the people. $15^{\text {th }}$ ed. München; Wien; Baltimore: urban and schwarzenberg; 1993. 
6. Dalziel JP, Noble VE. Bedside ultrasound and the assessment of renal colic: a review. Emerg Med J. 2013;30:3-8. [PubMed]

7. Brown DF, Rosen CL, Wolfe RE. Renal ultrasonography. Emerg Med Clin North Am. 1997;15:877-93. [PubMed]

8. Goertz JK, Lotterman S. Can the degree of hydronephrosis on ultrasound predict kidney stone size? Am J Emerg Med. 2010;28:813-6. [PubMed]

9. Moak JH, Lyons MS, Lindsell CJ. Bedside renal ultrasound in the evaluation of suspected ureterolithiasis. Am J Emerg Med. 2012;30:218-21. [PubMed]

10. Wolf JS. Nephrolithiasis: acute renal colic. Medscape Reference, 2011. Available at: http://emedicine.medscape. com/article/437096-overview

11. Chand RB, Shah AK, Pant DK, Paudel S. Common site of urinary calculi in kidney, ureter and bladder region. Nepal Med Coll J. 2013;15(1):5-7. [PubMed]

12. Scales CD Jr, Curtis LH, Norris RD, Springhart WP, Sur RL, Schulman KA, et al. Changing gender prevalence of stone disease. J Urol. 2007;177(3):979-82. [PubMed]

13. Luchs JS, Katz DS, Lane MJ, Mellinger BC, Stillman CA, Meiner EM, et al. Utility of hematuria testing in patients with suspected renal colic: correlation with unenhanced helical CT results. Urology. 2002;59(6):839-42. [PubMed]

14. Lin M, Schuur JD. A cost-effective way to evaluate patients with Recurrent Renal Colic. ACEP now. 2014;33(1).

15. Boyd R, Gray AJ. Role of the plain radiograph and urinalysis in acute ureteric colic. J Accid Emerg Med. 1996;13:3901. [PubMed]

16. Abrahamian FM, Krishnadasan A, Mower WR, Moran GJ, Talan DA. Association of pyuria and clinical characteristics with the presence of urinary tract infection among patients with acute nephrolithiasis. Ann Emerg Med. 2013;62:52633. [PubMed]

17. Patlas M, Farkas A, Fisher D, Zaghal I, Hadas-Halpern I. Ultrasound vs CT for the detection of ureteric stones in patients with renal colic. Br J Radiol. 2001;74(886):9014. [PubMed]
18. Middleton WD, Dodds WJ, Lawson TL, Foley WD. Renal calculi: sensitivity for detection with US. Radiology. 1988;167(1):239-44. [PubMed]

19. Fowler KA, Locken JA, Duchesne JH, Williamson MR. US for detecting renal calculi with nonenhanced CT as a reference standard. Radiology. 2002;222:109-13. [PubMed]

20. Turk C, Knoll T, Petrik A, Sarica K, Skolarikos A, Straub S, et al. Guidelines on Urolithiasis. European Association of Urology; 2015.

21. Golzari SE, Soleimanpour H, Rahmani F, Mehr NZ, Safari $\mathrm{S}$, Heshmat $\mathrm{Y}$, et al. Therapeutic approaches for renal colic in the emergency department: a review article. Anesth Pain Med. 2014;4(1): e16222. [PubMed]

22. Holdgate A, Pollock T. Systematic review of the relative efficacy of non-steroidal anti-inflammatory drugs and opioids in the treatment of acute renal colic. BMJ. 2004;328(7453): 1401. [PubMed]

23. Holdgate $\mathrm{A}, \mathrm{Oh} \mathrm{CM}$. Is there a role for antimuscarinics in renal colic? A randomized controlled trial. J Urol. 2005;174(2):572-5. [PubMed]

24. Romics I, Molnár DL, Timberg G, Mrklic B, Jelakovic B, Köszeqi $\mathrm{G}$, et al. The effect of drotaverine hydrochloride in acute colicky pain caused by renal and ureteric stones. BJU Int. 2003;92(1):92-6. [PubMed]

25. American College of Emergency Physicians Policy Statement: Emergency Ultrasound Guidelines. 2008.

26. Mandavia DP, Aragona J, Chan L. Ultrasound training for emergency physicians--a prospective study. Acad Emerg Med. 2000;7:1008-14. [PubMed]

27. Kartal M, Eray O, Erdogru T, Yilmaz S. Prospective validation of a current algorithm including bedside US performed by emergency physicians for patients with acute flank pain suspected for renal colic. Emerg Med J. 2006;23:341-4. [PubMed]

28. Watkins S, Bowra J, Sharma P, Holdgate A, Giles A, Campbell L. Validation of emergency physician ultrasound in diagnosing hydronephrosis in ureteric colic. Emerg Med Australas. 2007;19:188-95. [PubMed] 